\title{
AIAA-2002-0743
}

\section{CARS Thermometry in a Supersonic Combustor for CFD Code Validation}
A.D. Cutler, The George Washington University, Hampton, VA

P.M. Danehy

NASA Langley Research Center, Hampton, VA

R.R. Springer, The George Washington University, Hampton, VA

R. DeLoach, D.P. Capriotti NASA Langley Research Center, Hampton, VA

\section{0th AIAA Aerospace Sciences Meeting \& Exhibit 14-17 January 2002 / Reno, NV}

For permission to copy or republish, contact the copyright owner named on the first page. For AIAA-held copyright, write to AIAA, Permissions Department, 1801 Alexander Bell Drive, Suite 500, Reston, VA 20191-4344. 



\title{
AIAA-2002-0743 \\ CARS THERMOMETRY IN A SUPERSONIC COMBUSTOR FOR CFD CODE VALIDATION
}

\author{
A. D. Cutler", P. M. Danehy", R. R. Springer*, R. DeLoach ${ }^{\$}$, D. P. Capriotti" \\ NASA Langley Research Center. Hampton, VA 23681
}

\begin{abstract}
An experiment has been conducted to acquire data for the validation of computational fluid dynamics (CFD) codes used in the design of supersonic combustors. The primary measurement technique is coherent anti-Stokes Raman spectroscopy (CARS), although surface pressures and temperatures have also been acquired. Moderndesign-of-experiment techniques have heen used to maximize the quality of the data set (for the given level of effort) and minimize systematic errors. The combustor consists of a diverging duct with single downstreamangled wall injector. Nominal entrance Mach number is 2 and enthalpy nominally corresponds to Mach 7 flight. Temperature maps are obtained at several planes in the flow for two cases: in one case the combustor is piloted by injecting fuel upstream of the main injector, the second is not. Boundary conditions and uncertainties are adequately characterized. Accurate CFD calculation of the flow will ultimately require accurate modeling of the chemical kinetics and turbulence-chemistry interactions as well as accurate modeling of the turbulent mixing.
\end{abstract}

\begin{tabular}{ll} 
& \multicolumn{1}{c}{ Nomenclature } \\
$C_{N 2}$ & concentration of nitrogen \\
$k$ & thermal conductivity of wall $(\mathrm{W} / \mathrm{mK})$ \\
$n$ & number of samples \\
$p$ & number of parameters \\
$q$ & heal flux $\left(\mathrm{W} / \mathrm{m}^{2}\right)$ \\
$t$ & time $(\mathrm{s})$ \\
$T$ & temperature $(\mathrm{K})$
\end{tabular}

$x, y, z \quad$ position coordinates in right-handed system.

see Fig. $2(\mathrm{~m})$

$\alpha_{i} \quad$ thermal diffusivity of wall $\left(\mathrm{m}^{2} / \mathrm{s}\right)$

$\sigma$ standard deviation

\section{$\underline{\text { Introduction }}$}

Computational fluid dynamics (CFD) codes are extensively employed in the design of high-speed air breathing engines. CFD analysis based on the Reynolds averaged Navier-Stokes equations uses models for the turbulent fluxes that employ many ad hoc assumptions and empirically determined coefficients. Typically, these models cannot be applied with confidence to a class of flow for which they have not been validated. This experiment is one of several adopted by a working group of the NATO Research and Technology Organization (RTO) as a test case for their CFD development and validation activity. Another is a study of supersonic coaxial jets without combustion'. Calculations of the coaxial jet and the present geometry using the SPARK code ${ }^{2}$, performed in conjunction with the RTO activity, have been presented ${ }^{3}$.

The experiment is designed to provide a relatively simple case for CFD codes involving supersonic injection. mixing and combustion in a duct. The model geometry is simple and large regions of subsonic/recirculating flow are avoided. Care is taken to define the geometry and model inlet conditions. The enthalpy of the test gas (hot air "simulant") is nominally equivalent to Mach $7 \mathrm{flight}$. It was believed, on the hasis of calculations performed (e.g..

\footnotetext{
* Associate Professor, The George Washington University. MS 335. Senior Member AIAA

$\div$ Research Scientist. Instrumentation Systems Development Branch. MS 236. Member AIAA

$\Varangle$ Graduate Research Scholar Assistant. The George Washington Universily. Current address. Lockheed-Martin NE\&SS - Marine Systems. Member AIAA

$\$$ Senior Research Scientist. Instrumention Systems Development Branch. MS 236. Member AIAA

If Research Engineer, Hypersonic Airbreathing Propulsion Branch. MS 168.

fequipment brand names in this paper is for informational purposes only and should not the interpreted as an endorsement of these products by the authors. NASA or the US Government.

Copyright $\bigcirc 2002$ by the American Institule of Aeronautics and Astronautics. Inc. No copyright is asserted in the United States under Title 17. U.S. Code. The U.S. Government has a royalty-free license to exercise all rights under the copyright claimed herein for Governmental purposes. All other rights are reserved by the copyright owner.
}

\section{American Institute of Aeronautics and Astronautics}


Rel. 2), that this would produce mixing-limited flow, that is to say, one for which chemical reaction to equilibrium proceeds at a much greater rate than mixing. It later proved that this was not the case.

The primary experimental technique employed is coherent anti-Stokes Raman spectroscopy, known by its acronym CARS. An introduction to CARS is given by Eckbreth ${ }^{4}$, and an application of CARS to supersonic combustors is given by Smith et al. ${ }^{5}$. The species probed is molecular nitrogen and the quantity measured is temperature, although. If assumptions are made as to the relative proportions of the other major chemical species, composition can also be estimated. Composition data are not reported herein. CARS, like other optical techniques, does not significantly alter the flow being studied. Intrusive probes, such as Pitot, total temperature, hot-wire, etc., are not used due to access difficulty and high heat flux in the combustor, and because they may alter the flow. Also, CARS has several advantages over other optical methods. It is relatively mature and well understood. Signal levels are relatively high. The signal is in the form of a coherent (laser) beam, and can be collected through relatively small windows. Consequently, incoherent (non-CARS) interference can be rejected by spatial filtering.

Application of a complicated technique like CARS in high-speed engine environments is not routine. Since it is a pointwise (rather than planar) technique, building a "picture" of the internal temperature field of the combustor requires hundreds of facility runs, which is expensive. Thus, modern-design-of-experiments (MDOE) techniques are used to minimize the quantity of data required to meet the goals of this work. Due to the complexity of the experiment and the fact that, at the outset, the effects of important variables (including facility operation, model and instrumentation variables, etc.) are not fully understood, there are likely to be significant uncontrolled variables. MDOE techniques are used 10 minimize systematic errors associated with these.

\section{Flow Facility}

The experiment is conducted in NASA Langley's Direct-Connect Supersonic Combustion Test Facility (DCSCTF) $^{\dagger}$. Hot air simulant, known as vitiated air, is produced in the "heater", shown in Fig. 1. Oxygen and air are premixed and then hydrogen is burned in the oxygenenriched air. Flow rates are selected so that the mass fraction of oxygen in the vitiated air is the same as that of standard air. The high pressure, vitiated air is accelerated through a water-cooled convergent-divergent nozzle, before entering the test model. The facility is designed to
AIAA-2002-0743

test the combustor of a supersonic combustion ramjet (SCRAMJET) engine by directly connecting the facility nozzle exit to the entrance of the combustor. This facility is typically used in fundamental combustor research.

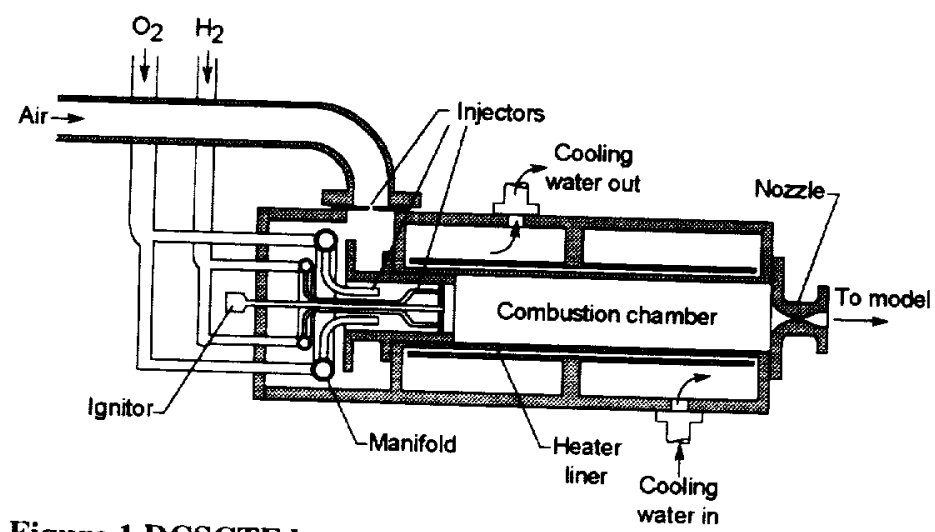

Figure 1 DCSCTF heater and nozzle.

The test conditions are nominally representative of Mach 7 flight. Gas flow rates to the heater are: $0.915 \pm 0.008 \mathrm{~kg} / \mathrm{s}$ air, $0.0284 \pm 0.0006 \mathrm{~kg} / \mathrm{s}$ hydrogen, and $0.300 \pm 0.005 \mathrm{~kg} / \mathrm{s}$ oxygen. The heater stagnation pressure is $0.765 \pm 0.008 \mathrm{MPa}$. All uncertainties presented in this paper are based on the $95 \%$ probability limits (1.98 times the standard deviation). The above uncertainties are due to the random run-to-run variations and do not include a $\pm 3 \%$ uncertainty in the mass flow rate measurements.

Heater and nozzle exit conditions are estimated from the flow rates, heater pressure, and nozzle minimum and exit areas using one-dimensional (ID) analysis ${ }^{7}$. The flow exiting the heater into the nozzle is assumed to be in thermodynamic equilibrium, but has unknown enthalpy due to heat lost to the structure and cooling water. The enthalpy is guessed and the area of the sonic throat computed by 1D analysis assuming isentropic flow in the nozzle. The enthalpy is then iterated until the computed area at the sonic throat equals the geometrical minimum area of the nozzle. Nozzle exit conditions are computed from the geometrical exit area. The composition at the nozzle throat and exit could be evaluated at frozen (at heater values) or equilibrium conditions. All significant minor species are included. Calculations assuming equilibrium and frozen composition differ in minor species concentration, but not significantly in major species, temperature or pressure. The nominal calculated conditions, and uncertainties due to mass flow rate measurement error and run-to-run variations in heater conditions are: heater stagnation temperature $1827 \pm 75 \mathrm{~K}$. exit temperature $1187 \pm 60 \mathrm{~K}$, exit pressure $100 \pm 1.5 \mathrm{kPa}$. exit Mach number 1.989 \pm 0.005 . Errors arising in the

\section{American Institute of Aeronautics and Astronautics}


calculation due to the assumption of $1 \mathrm{D}$ flow (the effects of non-uniform composition. boundary layers. etc.) are not considered.

A study of the flow quality at the exit of the facility nozzle was previously conducted ${ }^{8}$. A Pitot probe rake was employed to map the exit Pitot pressure and additionally the flowfield at the exit of the nozzle was visualized. Silane $\left(\mathrm{SiH}_{4}\right)$ was added to the heater hydrogen and burned to form silica particles in the heater. The particles were illuminated by a pulsed laser-sheet and imaged with a CCD camera. Results were compared to CFD calculations of the nozzle flow. The flow at the nozzle exit was not completely 1D, but the computed Pitot pressure distribution agreed well with measurement. The flow appeared well mixed.

The test model is shown in Fig. 2: flow direction is from left to right. The model consists of two main sections of duct: the copper upstream section and the carbon steel downstream section. Stainless steel flanges and carbon gaskets separate the sections from each other and the nozzle. Proceeding from left to right, there is a constant area segment, a small outward step at the top wall. a second short constant area segment followed by a constant $3^{\circ}$ divergence of the top wall. The span is constant at

(a)

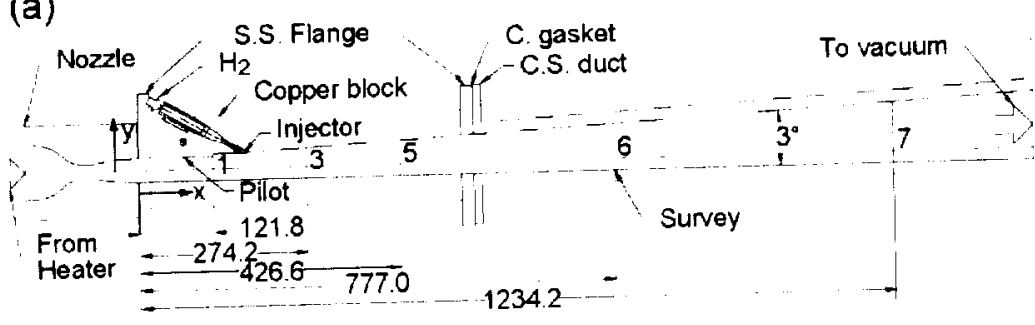

(b)

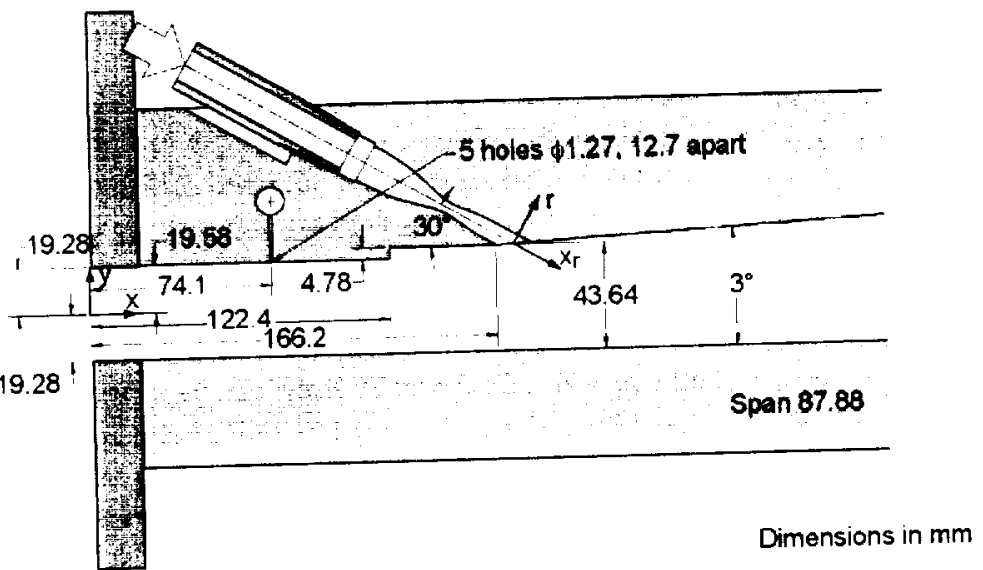

Figure 2 Test model: (a) nozzle, copper and steel duct sections, (b) detail in vicinity of fuel injector and pilots.
$8788 \mathrm{~mm}$. Five small pilot fuel injector holes are located ahead of the step. and the main fuel injector is located just downstream of the start of the $3^{3}$ divergence. The injection angle is $30^{\circ}$ to the opposite wall. The injector nozzle is designed by the method of characteristics to produce Mach 2.5, $1 \mathrm{D}$ flow at the injector exit. Hydrogen temperature of $302+4 \mathrm{~K}$, and equivalence $0.99+0.04$. On some runs, additional hydrogen injection provided by the 5 pilot injectors at the same nominat temperature and a total equivalence ratio of $0.1+8 \pm 0.008$. The pilots are turned on and off at the same time as the main fuel injector.

The duct is uncooled; however. the wall thickness of the copper duct is greater than $32 \mathrm{~mm}$ and the carbon steel duct is $19 \mathrm{~mm}$. Thus, given the good thermal conductivity of these materials, it is possible to operate the facility with the model fueled for run times in excess of $20 \mathrm{~s}$ (and unfueled for much greater times). With atmospheric temperature air flowing in the model between runs, runs

The model is equipped with 7 slots to allow the CARS beams to penetrate the duct. of which slots 1.3 .5 . 6. 7, depicted in Fig. 2(a), are used in this study. The slots are in pairs. one on each side of the duct. $4.8 \mathrm{~mm}$ wide, extending the full height of the duct. When not in use the slots are plugged flush to the wall. Windows covering the slots are mounted at the end of short rectangular tubes, at the Brewster angle to minimize reflections (Fig. 3 ). The window tubes are ventilated with a constant flow of electrically heated ( $400 \mathrm{~K}$ ) dry air to prevent condensation of water on the windows. The C.ARS beams focus can thus be translated the full span and height of the duct without damaging the windows.

The model is instrumented with both pressure taps and wall temperature probes. The details of this instrumentation are different in the upstream and downstream duct sections. Thirty-five static pressure taps are located in the copper duct, consisting of $0.80 \mathrm{~mm}$ diameter square-edged holes. Taps are located on the bottom wall. at the centerline. and on the top wall at $z=-36.3 \mathrm{~mm} z$ is measured from the horizontal center

American Institute of Aeronautics and Astronautics 
line). Forty-nine static pressure taps are located in the steel duct, consisting of $1.6 \mathrm{~mm}$ diameter square-edged holes. Taps are located at top and bottom wall centerlines, and sidewall midpoints. Pressures are measured with an accuracy of $\pm 0.6 \mathrm{kPa}$ by a Pressure Systems Inc. electronically scanned pressure-measuring system.

Six spring-loaded, bayonet, ribbon, K-type thermocouples from Nanmac Corp. are located in 6.35 $\mathrm{mm}$ diameter blind holes in the copper block. The bottom of these holes is square and the wall thickness (to the duct interior surface) is $2.8 \mathrm{~mm}$. The thermocouple junction is located at the bottom of the hole at the center. This diameter and wall thickness are chosen, based on a multidimensional heat transfer analysis, so that the thermocouple would measure the unperturbed duct surface temperature. While the temperature at the bottom of the hole is less than local duct surface temperature, the effect of the hole, which alters the conduction path, is to raise the local duct surface temperature, and these effects offset. Six "eroding" K-type thermocouples from Nanmac Corp., $7.9 \mathrm{~mm}$ diameter and incorporating a carbon-steel sheath, are located in the carbon-steel duct. The thermocouple junction for these probes is located flush to the duct flow surface. Over time, the junction is removed by the hot flow, but can be regenerated using sandpaper. Since the probe material is predominantly carbon-steel. the same as the duct, this probe also measures the unperturbed duct surface temperature.

\section{Optical System}

\section{CARS Technique}

The CARS system uses an unseeded Spectra-Physics DCR-4 pulsed Nd:YAG laser frequency doubled to 532 $\mathrm{nm}$. The nominal power is $550 \mathrm{~mJ}$ per pulse in the green, repetition rate is $10 \mathrm{~Hz}$, and nominal line width is less than $1 \mathrm{~cm}^{-1}$. Beams are horizontally or "p" polarized with respect to the plane of the optical system. A broadband dye laser is employed in the system. This laser consists of an oscillator cavity, formed between a total reflecting mirror and a $30 \%$ reflector, and a single amplifier stage. Two identical dye cells are used, one in the oscillator and one the amplifier, through which flows rhodamine 640 in methanol. After separating the $532 \mathrm{~nm}$ from residual 1064 $\mathrm{nm}$ with dichroic mirrors, the $532 \mathrm{~nm}$ beam is split. One beam with $45 \%$ of the total power is used to pump the dye laser, split $22 \%$ to the oscillator and $78 \%$ to an amplifier. Pump beams are loosely focused on the dye cell, nearly parallel to the dye laser beam. Cell windows are at the Brewster angle to minimize reflections and ensure the dye laser is " $p$ " polarized. The wavelength is centered between $605 \mathrm{~nm}$ and $606 \mathrm{~nm}$ by adjusting the dye concentration,
AIAA-2002-0743

matching the Raman shift of nitrogen.

Figure 3 shows a schematic of the remaining components of the CARS system. The second $532 \mathrm{~nm}$ beam is split into two parallel, roughly equal intensity beams. The dye beam is expanded in a beam expander (B). Dye and $532 \mathrm{~nm}$ beams are combined at a dichroic mirror (C) and are relayed via a periscope to a spherical (focusing) lens (SL) of focal length $0.41 \mathrm{~m}$. All three beams cross at their focal points: the focal point of the dye beam is made coincident with the focal point of the 532 $\mathrm{nm}$ beams by adjusting the beam expander. Beams are phase matched in a vertical planar BOXCARS configuration ${ }^{3}$.

At the lens, the full (to $\sim 10 \%$ of peak) diameter of the $532 \mathrm{~nm}$ beams is $\sim 8.5 \mathrm{~mm}$, and the beams are $18 \mathrm{~mm}$ apart. The full diameter of the dye is $\sim 11 \mathrm{~mm}$. At the focus, the diameters are respectively $\sim 0.12 \mathrm{~mm}$ and $~$ $0.15 \mathrm{~mm}$, yielding a geometrical beam intersection length of $5.4 \mathrm{~mm}$. The length of the measurement volume is measured by translating the CARS measurement volume through a thin planar jet of nitrogen, surrounded by a coflowing jet of helium. The length over which CARS signal is recorded is $\sim 4.5 \mathrm{~mm}$ and the full width half maximum (FWHM) of the signal distribution is $\sim 2.25$ $\mathrm{mm}$. The measurement volume length is selected (by selecting the spacing of the beams on the lens) as a compromise between the desire to have high spatial resolution and high signal power. The following heam energy levels per pulse are obtained at the focusing lens: $\sim 85 \mathrm{~mJ}$ for each of the green, from $12 \mathrm{~mJ}$ to $24 \mathrm{~mJ}$ for the dye.

The beams (including the CARS signal beam) are relayed via a second spherical (collimating) lens and a second periscope back to the optical bench. The overlapping CARS and $532 \mathrm{~nm}$ beams are separated in a splitter (S). The splitter consists of two $100 \mathrm{~mm}$ long dichroic mirrors that reflect $299.5 \%$ of the incident CARS signal while reflecting only $\sim 20 \%$ of the $5.32 \mathrm{~nm}$, transmitting the rest. The CARS and $5.32 \mathrm{~nm}$ beams enter the splitter at $45^{\circ}$ to the mirrors and undergo six back-andforth reflections. The beam is then directed through additional filters as needed to reject residual $5.32 \mathrm{~nm}$ or for CARS signal attenuation. It enters a polarizer that allows only p-polarized light to pass (not a critical component since it is found that the signal is already well polarized). It is then focused by a pair of cylindrical lenses (CL) and enters a $1 \mathrm{~m}$ monochrometer with 1200 groove/mm grating via an aperture (E). An EG\&G PAR model 1420 intensified, linear, self-scanned silicon photodiode array detector (IPDA) is mounted at the exit plane of the detector. The detector consists of 1024

\section{American Institute of Aeronautics and Astronautics}


AIAA-2002-0743

elements. $2.5 \mathrm{~mm}$ high by $25 \mathrm{um}$ wide, of which the central 598 elements are used. The cylindrical lenses are adjusted to produce a horizontal focus at the detector (maximizing image sharpness) and a loose vertical focus (to ensure the detector provides a linear response to signal ${ }^{\prime)}$. An optical splitter ( $\left.X\right)$ is located in front of the detector ${ }^{10}$. The splitter creates a secondary signal on the detector, identical to the primary but offset by 290 pixels and of $6.1 \%$ the intensity. When the intensity of the primary signal exceeds the dynamic range of the detector. the secondary signal is used for analysis

The two top prisms of the periscope are mounted on stepping motor driven vertical translation stages. The two bottom prisms and the vertical translation stages are mounted on similar horizontal stages. By translating the vertical and/or horizontal stages in tandem (maintaining alignment) the measurement volume could be moved in the $y$ and/or a direction. It is important that the beams are

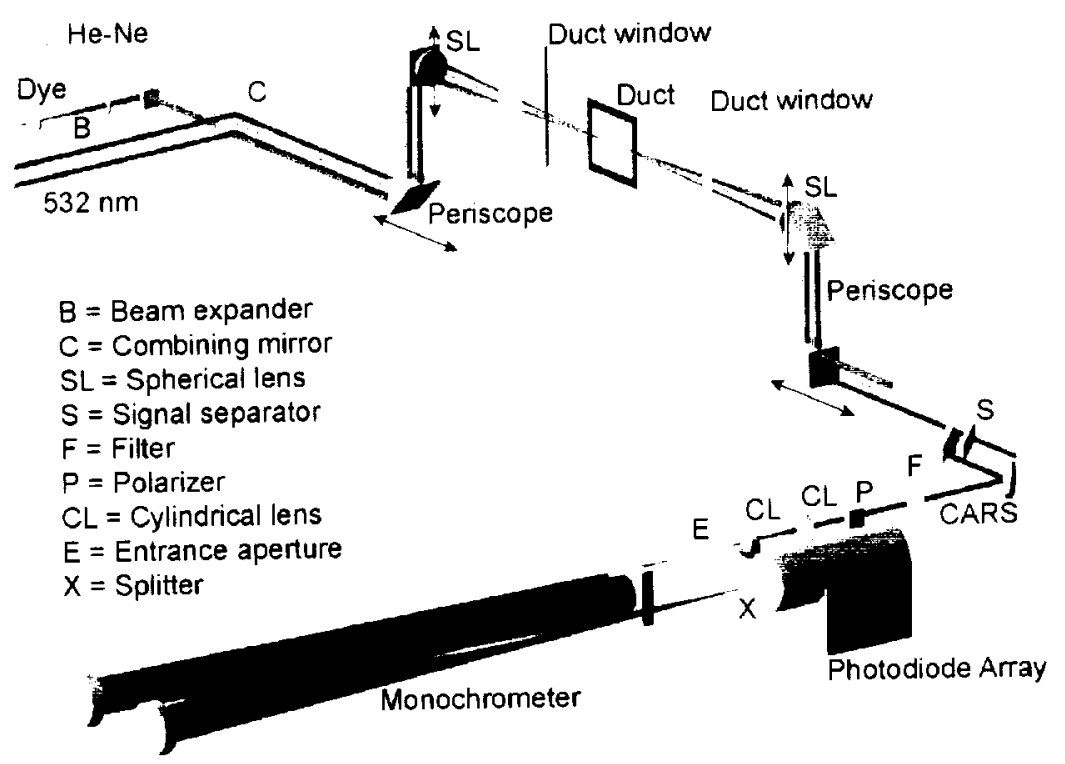

Figure 3CARS system: beam combining optics, intersection and signal detection optics.

parallel to the direction of motion of the translation stage. A reference, low-power helium-neon laser ( $\mathrm{He}-\mathrm{Ne}$ ) beam is directed through the periscopes, parallel to the direction of motion of both sets of stages. and through the center of the spherical lenses. The Nd:YAG and dye laser beams are periodically realigned by ensuring that they intersect the He-Ne beam at their focus.

CARS data acquisition is under the control of a personal computer ( $\mathrm{PC}$ ). The $\mathrm{PC}$ provides a continuous sequence of pulses to trigger the laser and synchronize the IPDA. The IPDA and translation stage controllers are initialized prior to data acquisition. When data is to be acquired. a control pulse is sent to the IPDA and translation stage controller, which then execute preprogrammed sequences. The IPDA scans at $30 \mathrm{~Hz}$ : scans $1,4,7$ etc. are clearing scans and are not saved. scans 2, 5.8, etc. are prescans, and scans 3.6.9. etc. are data scans. coincident with the laser pulse. After completion of acquisition. resultant IPDA data is transferred to the PC. Two types of acquisition are employed. In the first, data is acquired at a single point in space. In the second. data is acquired while either the vertical or the horizontal stages are in constant velocity motion.

CARS data are acquired in the supersonic combustor during multiple sets of test runs. During a set of runs (which might last as long as 5 hours), access to the model and optical system is prohibited for safety reasons. Test runs consisted of approximately $5 \mathrm{~s}$ during which the heater is operating but no fuel is injected in the model, followed by from $11 \mathrm{~s}$ to $20 \mathrm{~s}$ during which fuel is injected. CARS data is acquired over a period $2 \mathrm{~s}$ shorter than the period of fuel injection. Immediately after a run. $10 \mathrm{~s}$ of data is acquired with the system operating as before, the dye laser beam blocked by a remotely operated flag. These "background" scans measure non-CARS interferences such as scattered laser light. Dye laser spectra are acquired simultaneously with each data run by sampling with a fiber optic probe coupled to an Instaspec $1 / 4 \mathrm{~m}$ spectrometer with a CCD detector. controlled by a separate PC.

Just betore and just after a set of test runs, "reterence" CARS spectra are acquired in a low speed jet of "PCDuster" refrigerant gas. Since this jet contained no nitrogen, and is of constant CARS susceptibility. the spectra reflect the spectral variation in dye laser power. Additionally, spectra are acquired with room temperature air flowing in the duct.

The test facility poses problems in relation to the operation of the CARS system. The effect of acoustic and structural vibration is not significant. However. large temperature swings are common since the room in which the apparatus operated is continuously ventilated with external atmospheric air: additionally significant heat is radiated from the model. Thermal expansion effects on the

\section{American Institute of Aeronautics and Astronautics}


mechanical components of the optical system are not sufficient to require remote adjustments (adequate signal levels are typically maintained for several hours). However, thermal expansions significantly change dye laser center wavelength and power.

\section{Data Reduction}

CARS data are analyzed on a separate workstation. Prescans are subtracted from data scans. Background scans (after subtraction of prescans) are averaged and subtracted from data scans. Both primary and secondary (produced by the splitter) CARS signal are contained within the data scian. If the primary is saturated. the secondary is selected for analysis. Data scans are divided by the reference spectrum to remove the effect of the dye laser spectral power distribution. and normalized to unit area (primary or secondary). Data are compared to a library of similarly normalized theoretical spectra to determine the temperature and nitrogen concentration. The pixel location of the start of the theoretical spectra is allowed to tloat \pm 10 pixels from a nominal position in 0.3 pixel increments. The combination of temperature. concentration, and pixel location that produces the least mean square deviation between theory and data is selected.

Theoretical CARS spectra are generated using the program CARSFT". The combustion gases are assumed to be a mixture of nitrogen and non-resonant buffer gas. both having non-resonant susceptibility of $8.5 \times 10^{-18}$ $\mathrm{cm}^{3} / \mathrm{erg}$. The nominal static pressure is assumed to be 1 atmosphere. In fact, as may be seen in Fig. 7, the pressure at the CARS planes is as much as $20 \mathrm{kPa}$ below and 35 $\mathrm{kPa}$ above. The error introduced by this assumption is estimated by calculating theoretical spectra over a range of pressures and temperatures and fitting to them assuming 1 atmosphere pressure. The difference between fit and true temperatures (fit minus true) is about $25 \mathrm{~K}$ per $10 \mathrm{kPa}$ difference from 1 atmosphere for $T \mathrm{~s}$ near $2000 \mathrm{~K}$. The Exponential Gap Model for collisional narrowing of the Raman line shape is used: a Voigt model was also tried and found to make little difference for the test conditions. A $532 \mathrm{~nm}$ laser line width of $1 \mathrm{~cm}^{-1}$ is assumed: spectra are not sensitive to $532 \mathrm{~nm}$ laser line width for the test conditions. An experimentally determined instrument probe function is used. Temperatures from $150 \mathrm{~K}$ to $3000 \mathrm{~K}$ in increments of 25 $K$. and 29 non-uniformly spaced concentrations of nitrogen are used in the library. Typical spectra at several temperatures and concentrations are shown in Fig. 4 giving an indication of the sensitivity of the spectra to these variables

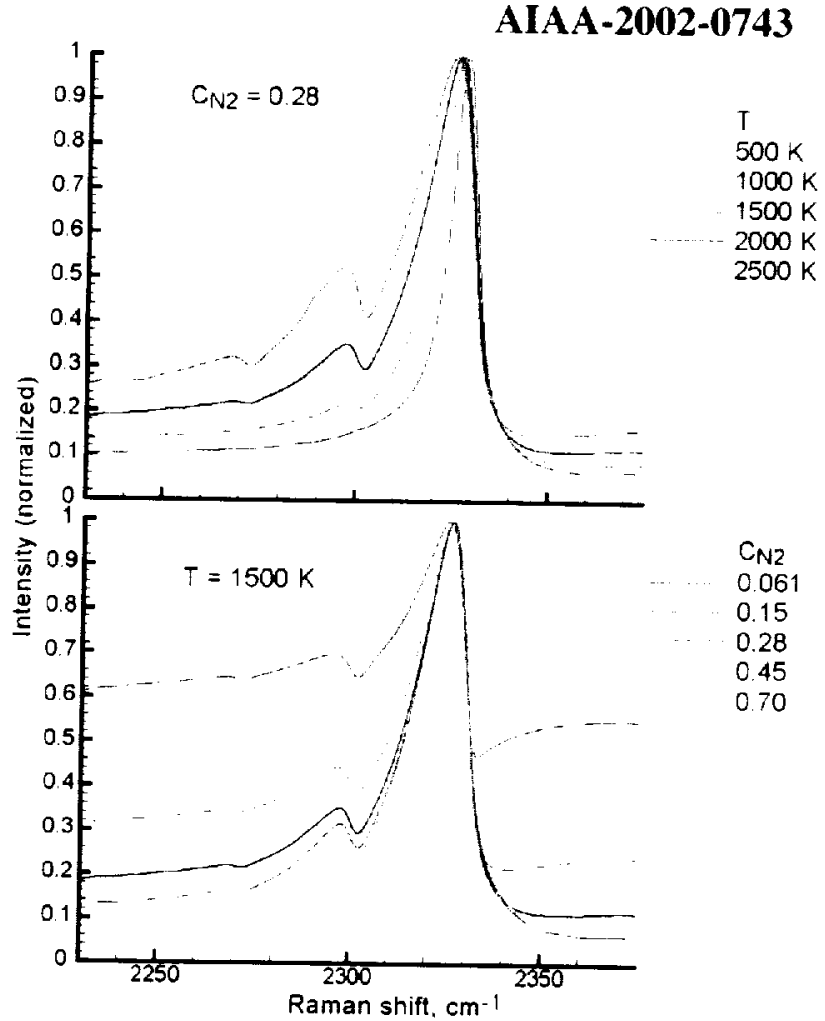

Figure 4 Theoretical CARS spectra

The peak of the reference CARS spectrum shifts significantly during a set of runs. This shift can be attributed largely to a shift in the dye laser wavelength. However, there are other factors. Thermal effects on mechanical components of the optical system. beam steering by the hot gases in the duct, and even translation of the periscope stages all can change the position of the CARS beam focus at the entrance slit to the monochrometer, and hence the position of the spectra on the detector. Two techniques are employed to correct for this problem. The first is to allow the pixel location of the start of the theoretical CARS spectra to float in the fitting process, as described. The second is to estimate the reference spectrum from the run data itself. The technique is inspired by the observation that the directly measured dye-laser spectra could be accurately fit to a Gaussian function.

The procedure is illustrated in Fig. 5. The first step is to analyze the data from a given run using the reference spectrum obtained with the refrigerant gas at the end of a set of runs. For a particular laser pulse, spectrum $A$ is the best-fit theoretical CARS spectrum, B is the measured CARS spectrum (prior to normalization by the reference spectrum), and $C$. the ratio of $B$ to $A$. is an estimate of the reference spectrum for this particular shot. All such estimates for a given run are averaged, and then fit to a

\section{American Institute of Aeronautics and Astronautics}




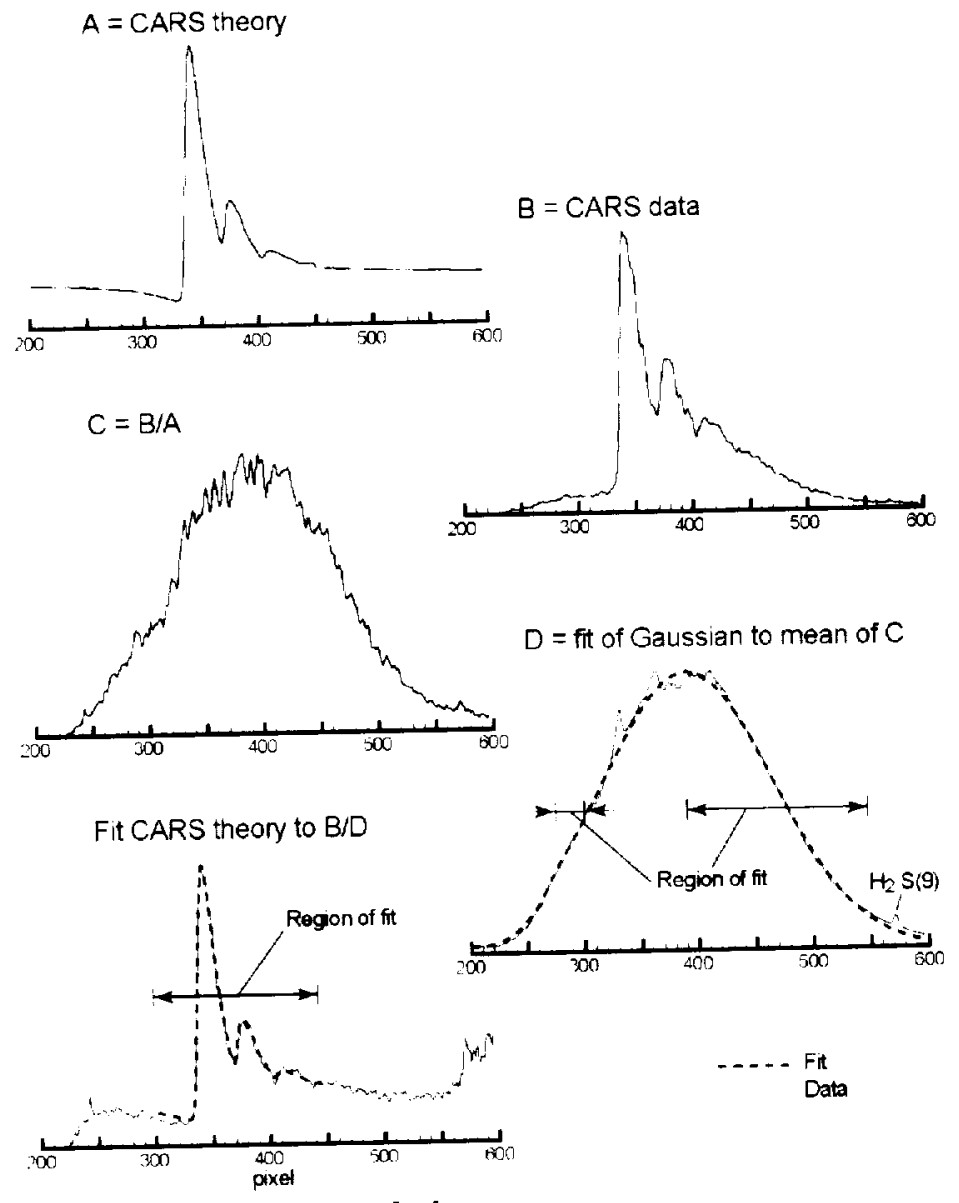

Figure 5 CARS data analysis

Gaussian function for amplitude. center and width. The region of fit is indicated in the figure, and excludes a region around the bandhead of nitrogen (which was very noisy), and the region to the left of pixel 275 (potentially affected by masking from the optical splitter). As a practical matter, it is necessary to exclude from the average individual spectra for which good fits to theory could not be obtained. Acceptable averages for fitting could be found for almost all runs. The Gaussian fit. D. is then used as the reference spectrum for normalization of all data for the given run. The figure shows data from a laser pulse after normalization. and the best fit theoretical spectrum. This procedure is typically iterated twice, with the latest best-fit theoretical spectrum used to determine an improved reference spectrum.

The techniques used for acquisition and analysis of CARS data in the supersonic combustor are tested in a "Hencken" adiabatic, flat-flame burner burning hydrogen in air. Equivalence ratio (ratio of hydrogen rate to stoichiometric hydrogen rate for given air flow) is varied
AIAA-2002-0743

and the measured temperature compared to a calculation based on measured flow rates and equilibrium chemistry (including minor species). The mean temperatures for several $10 \mathrm{~s}(100$ laser pulse) runs are shown in Fig. 6. The equivalence ratio is accurate to within $\pm 3 \%$. Included in the data are runs at an equivalence ratio of one. in which the total laser power is varied from $200 \mathrm{~mJ}$ to $550 \mathrm{~mJ}$. Also included are data in which. through the use of different neutral density filters, the signal in the primary is saturated. forcing use of the secondary in analysis. No trends are found with either of these variables. indicating that the nitrogen spectrum is not saturated by high laser powers and that the splitter device works well. The average of all the data points at an equivalence ratio one is 2360 $\mathrm{K}$, compared to the theoretical value of $2380 \mathrm{~K}$. Standard deviations of the runs are shown. The trend with increasing laser power is to lower standard deviations owing to increased signalto-noise ratios. The standard deviation of the individual (single laser pulse) measurements at an equivalence ratio of one about the overall average is approximately $100 \mathrm{~K}$. Thus, $100 \mathrm{~K}$ may be taken as a conservative estimate of the standard deviation inherent in the CARS instrument.

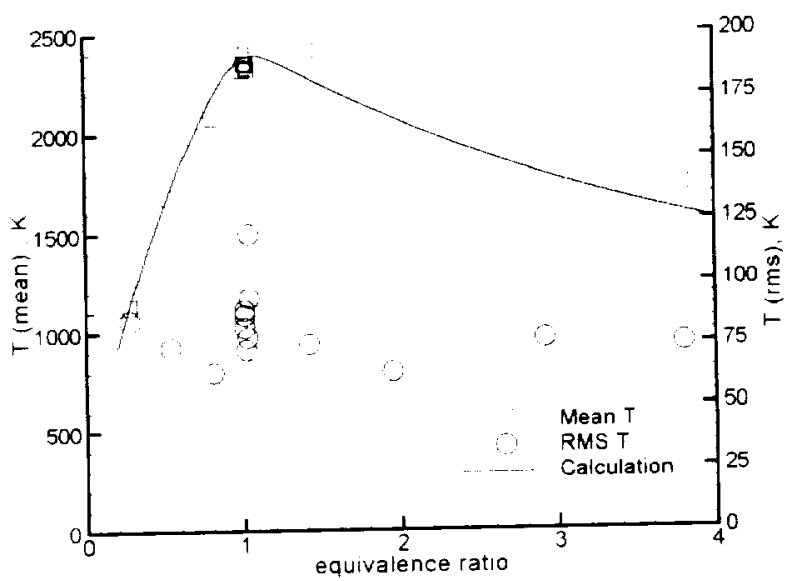

Figure 6 Comparison of theory and data in an adiabatic flame

The measurements agreed satisfactorily with calculation at an equivalence ratio less than or equal to one. However, for hydrogen rich flames. the measured temperature is. on average, nearly $150 \mathrm{~K}$ high. It is suspected that this is a problem with the way the CARS spectra are modeled in the presence of excess hydrogen, rather than with the experiment. For example. the 
hydrogen $S(10)$ rotational line is located at a Raman shift of $2267.5 \mathrm{~cm}^{-1}$ (compare Fig. 4) $)^{12}$. Hydrogen is not specifically included in calculating the spectral libraries. However, comparison of measured spectra with calculated spectra that include the line suggest that its presence is not alone sufficient to explain the discrepancy observed. This problem is being investigated, but for now it is accepted that measured temperature may be $\sim 150 \mathrm{~K}$ high in hydrogen rich regions.

\section{Modern Design of Experiments Randomization}

When repeated measurements or "replicates" made within a relatively short interval of time are more alike than otherwise identical replicates acquired over a longer time period, the observations are not independent. This condition is common in real experiments, and is caused by often unrecognized sources of systematic variation that persist over time, such as instrumentation drift, temperature effects, operator fatigue and learning effects. Sample means and variances estimated under such conditions are biased by generally non-reproducible functions of the systematic variation, which render the experimental results difficult to duplicate and of dubious value for confirming the predictions of computational models. Standard references on experiment design treat this phenomenon in detail. ${ }^{13.14 .15}$

Fisher ${ }^{16}$ recognized that independent observations occur less frequently in nature than generally assumed, and proposed the simple act of randomizing the set-point levels of independent variables as an effective way to ensure independence in case nature neglected to do so in some inopportune phase of an experiment. For example, if a horizontal scan of temperature is planned for several uniformly spaced locations across an operational supersonic combustor model. Fisher would recommend that the spatial coordinates be selected in random order rather than systematically. If the spatial coordinates are selected in a monotonically increasing sequence, starting on the left side of the supersonic combustor duct and proceeding systematically toward the right side, for example, wall-heating effects could cause measurements made on the right side of the duct to be biased high relative to measurements made on the left. This would impose an artificial asymmetry on the spatial dependence of temperature across the duct. However, if the spatial coordinates are selected in random order, some of the measurements made on the left would occur earlier and some would occur later, and similarly for the right side, ensuring that the effect of all time-varying systematic errors (not just wall effects) would then be independent of
AIAA-2002-0743

spatial coordinates. This would defend against artificial asymmetries that might otherwise occur. For these reasons, spatial set-points are set in random order in this experiment.

\section{Response Surface Methods}

Response surface methods are applied in this study, in which the spatial dependence of temperature is represented in each of a number of planes in a supersonic combustor duct by a mathematical function of the spatial coordinates. This method has the potential for providing a very compact representation of the temperature distribution, by replacing a potentially large volume of individual measurements with a relatively small set of numerical coefficients that can be used to adequately predict the temperature for any combination of spatial coordinates within the range examined in the experiment. The method has the additional virtue that it provides estimates of the response variable (temperature) for combinations of the independent variables (coordinates) that are not physically set in the experiment.

Because the response models are based on experimental data afflicted with uncertainty, predictions made with these models will likewise feature some degree of uncertainty. The specific uncertainty associated with any one model prediction depends on the variance in the response data used to develop the model, the number and location of points from which the model is fitted, the nature of the model itself (number and form of individual model terms), and the specific coordinate location for which the prediction is to be made. However, Box and Draper ${ }^{17}$ show that the average variance across points used to fit the model is simply $p \sigma^{2} / n$, where $p$ is the number of parameters in the model, $n$ is the number of points used to fit the model, and $\sigma$ is the standard deviation of those data.

An inverse relationship between data volume and inference error risk characterizes all experimental investigations. In this case, for a given functional form of the model (which determines $p$ ), and a given measurement environment (which determines $\sigma$ ), the average model prediction uncertainty can be driven to arbitrarily low levels by selecting a large enough volume of data, $n$. Conversely, by establishing in advance the levels of uncertainty that are acceptable, the volume of data necessary to achieve stated precision goals can be computed. This is useful in the design of an experiment, because it can reveal in advance when insufficient resources are available to acquire data in a volume necessary to achieve minimum precision requirements, and it can also prevent the acquisition of substantially

\section{American Institute of Aeronautics and Astronautics}


AIAA-2002-0743

more data than necessary to ensure acceptable levels of inference error risk. In the present study. for example. standard deviations in supersonic combustor temperature. $\sigma$. as high as $.300 \mathrm{~K}$ are typical. (It should be emphasized that this high $\sigma$ is due primarily to real turbulent fluctuations in the flow rather than instrument precision.) A typical response model might have 20 terms. $p$. To ensure an average standard error for the response model that is no greater than $25 \mathrm{~K}$. say, a 2880 -point sample of data would have to be acquired in each plane. This may be as much as an order of magnitude fewer points than would be acquired if response surface methods are not employed.

Data volume estimates are increased when resolution requirements are added to the precision requirements (e.g. minimum temperature differences that must be resolved). but the same inverse relationship exists between data volume and inference error risk. Several excellent references provide additional details on response surface methods. ${ }^{1+18.11^{4}, 20}$

\section{Results}

Surface Pressure and Temperature

Surface pressure and temperature data are presented for two typical runs, one in which the pilot injectors are operating and one in which they are not. These runs are chosen because the gas flow rates to the heater, injector and pilot and the heater pressure are all very close to the respective averages over the total set of tuns.

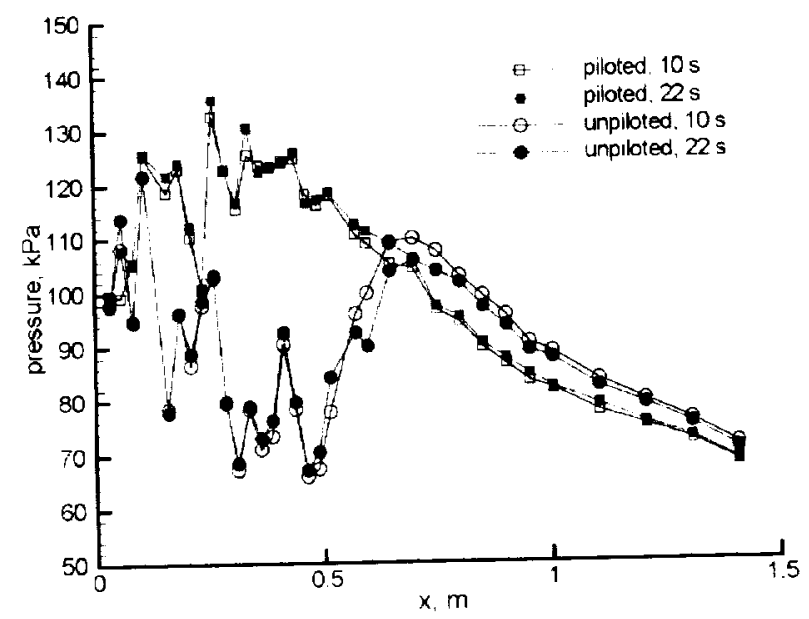

Figure 7 Surface pressure distributions along centerline of bottom wall.

Surface pressure distributions for the pressure taps at the bottom wall centerline, averaged over 1 s intervals, are shown in Fig. 7. Data are shown at $10 \mathrm{~s}$ and $22 \mathrm{~s}$ into the run: the heater is initiated at time $t_{i}=1 \mathrm{~s}$ and fuel injection commences at time $t_{1}=6.0 \mathrm{~s}$ (piloted) or $6.4 \mathrm{~s}$ (unpiloted). Pressures vary widely in the upstream region due to the complex nature of the shock wave system created by the injectors and step. The pressure for the piloted case is higher than the unpiloted case between the pilot $(x=0.074 \mathrm{~m})$ and about $x=0.7 \mathrm{~m}$. due to combustion of gas from the pilot and main fuel injector. In the unpiloted case, pressure generally falls moving downstream due to divergence of the duct. until $0.5 \mathrm{~m}$ where it rises rapidly, peaking at about $0.75 \mathrm{~m}$. Presumably. there is minimal combustion upstream of this region. Downstream of $0.75 \mathrm{~m}$ the pressure drops smoothly in both cases but is higher in the unpiloted case. despite the greater total injected fuel rate in the piloted case. Differences between the two cases suggest that significant combustion of the fuel does not take place upstream of $0.5 \mathrm{~m}$ in the unpiloted case. but that the combustion then proceeds to completion by $0.75 \mathrm{~m}$. It is not expected that fuel and air are fully mixed at $0.75 \mathrm{~m}$. so that further mixing and combustion is expected to occur downstream. Comparison between measurements at $10 \mathrm{~s}$ and at $22 \mathrm{~s}$ reveals only small differences. There is no suggestion that the combustion delay experienced by the unpiloted case is affected by the increase in surface temperature that occurs during the course of a run. Surface pressure varies as much as $20 \mathrm{kPa}$ or more between top. bottom, and sidewall taps (not shown) upstream of about $0.65 \mathrm{~m}$, consistent with the effects of shock waves. Downstream of this point, there are no differences between the walls.

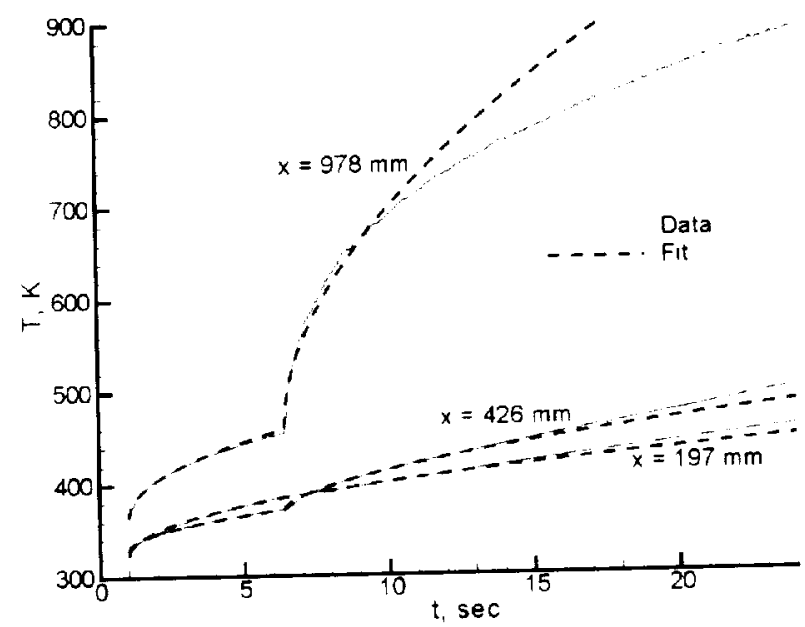

Figure 8 Wall temperature history, unpiloted, top wall: data and fits.

Since the duct is uncooled, surface temperatures vary greatly during the course of the run. In the copper section. temperature is typically about $\sim 360 \mathrm{~K}$ at the start

\section{American Institute of Aeronautics and Astronautics}


of tuel injection but rises to as high as $\sim 610 \mathrm{~K}$. In the carbon steel section. it typically is $\sim 440 \mathrm{~K}$ at the start and as high as $\sim 950 \mathrm{~K}$ at the end. These variations in surface temperature are least-squares fit to the solution for wall temperature of a semi-intinite body at initially uniform temperature $T_{1}$. subject to steps in surface heat flux from zero to $q_{0}$ at time $t_{0}$ and from $q_{0}$ to $q_{10}+q_{1}$ at $t_{1}$ :

$$
\begin{aligned}
& T_{w}-T_{i}=\frac{2 q_{0}}{k_{s}} \sqrt{\frac{\alpha_{s}\left(t-t_{0}\right)}{\pi}} \text { for } t_{0} \leq t<t_{1} \\
& T_{n}-T_{i}=\frac{\left.2 q_{0}\right)}{k_{s}} \sqrt{\frac{\alpha_{y}\left(t-t_{0}\right)}{\pi}}+\frac{2 q_{1}}{k_{s}} \sqrt{\frac{\alpha_{s}\left(t-t_{1}\right)}{\pi}} \text { for } t \geq t_{1}
\end{aligned}
$$

The fit parameters are $T_{i}, q_{1}$, and $\psi_{1}$ and the fit is conducted out to $t=11 \mathrm{~s}$.

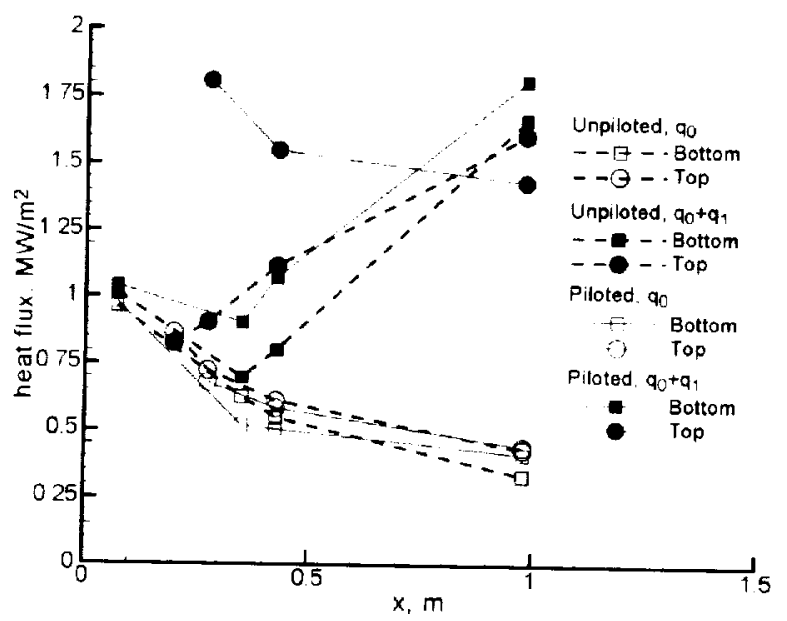

Figure 9 Surface heat flux distributions: top and bottom walls, centerline

Representative temperature histories and fits (top wall. unpiloted) are shown in Fig. 8. Fits often diverge from the data beyond $11 \mathrm{~s}$. indicating that heat flux continues to change slowly during the run. The material property $\sqrt{\alpha_{s}} / k_{s}$ is taken to be $36.7 \mathrm{~kW} \mathrm{~K} / \mathrm{m}^{2} \mathrm{~s}^{1 / 2}$ for the copper duct and $12 \mathrm{~kW} \mathrm{~K} / \mathrm{m}^{2} \mathrm{~s}^{1 / 2}$ for the steel duct. These values have not been verified experimentally, so this analysis should not be relied upon except in a relative sense (i.e., case to case, location to location within the copper duct. injection to no injection). Heat fluxes are presented in Fig. 9. both top and bottom walls, on the centerline. Heat flux varies in the range $1.0 \mathrm{MW} / \mathrm{m}^{2}$ to 0.3 $\mathrm{MW} / \mathrm{m}^{2}$ before injection $\left(q_{0}\right)$, and in the range $0.7 \mathrm{MW} / \mathrm{m}^{2}$ to $1.8 \mathrm{MW} / \mathrm{m}^{2}$ with injection $\left(q_{0}+q_{1}\right)$. Note that. before injection. heat tlux at a given location varies $10 \%$ to $30 \%$ from case to case. probably reflecting variation in the initial temperature of the wall between runs. With injection. heat flux at downstream locations shows a large increase relative to before injection due to combustion.
AIAA-2002-0743

Large increases occur in the piloted case on the top wall, downstream of the main injector $(x=0.166 \mathrm{~m})$, indicating the presence of combustion products near the wall. In the unpiloted case, a smaller heat flux rise occurs ahead of 0.5 $m$ (where the pressure rise starts), indicating either the start of combustion near the wall. or an increase in heat transfer coefficient. An increase in heat transfer coefficient would be expected to occur under the injection-induced streamwise vortex pair.

\section{CARS Temperatures}

Data is acquired over 201 facility runs over 10 test days. Except for one day, when laser beams clipped the edge of the duct window slots due to thermal expansion and movements of the duct, the vast majority of the data are found acceptable and analyzed. Data are acquired at 6 or 7 fixed points near the horizontal centerline. $6 \mathrm{~s}$ with only the heater operating followed by $18 \mathrm{~s}$ with both heater and fuel injected. Data are also acquired during 16 $s$ of horizontal motion of the translation stages at $5 \mathrm{~mm} / \mathrm{s}$. or from $9 \mathrm{~s}$ to $18 \mathrm{~s}$ of 5 or $6 \mathrm{~mm} / \mathrm{s}$ vertical motion. during which time fuel is continuously injected. Figure 10 is a 3dimensional cutaway view of the duct with the locations of the data points overlaid.

Ideally, each consecutive data point would be acquired at a randomly selected location and plane. Reallite constraints prevent this. Motion from one point to the next takes significant time: if it is required to move between randomly selected points during the course of a limited-time facility run, the number of data points acquired would be considerably reduced. Changing from one plane to the next required shutdown of the facility and hardware changes. Thus, all data at a given plane are acquired consecutively. Data are acquired either at the fixed points or during continuous constant velocity motion, as described. However, the order of this data acquisition and directions of the individual motions is randomized.

The CARS temperature data are all tit to a cosine series bivariate function of order 5 at plane 1 and order 6 at the other planes, with the number of fit parameters respectively 21 and 28 . Fits are pertormed using commercial software ${ }^{21}$. The number of data points acquired per plane is from 2000 to 4000 and the standard deviation of the data from the fit at the various planes ranges from $196 \mathrm{~K}$ to $304 \mathrm{~K}$. Thus, the fitted functions represent an estimate of the mean temperature distribution with mean uncertainty. given by $1.98 \sigma \sqrt{p / n}$, from $36 \mathrm{~K}$ to $59 \mathrm{~K}$ depending on the plane. It is important to point out that the uncertainty in the surface fits to the data is lower near the center of the measurement plane and higher

\section{American Institute of Aeronautics and Astronautics}


near the edge. This uncertainty does not include the effect of the previously noted error in fuel rich regions of the flow, or any other non-randomized error.

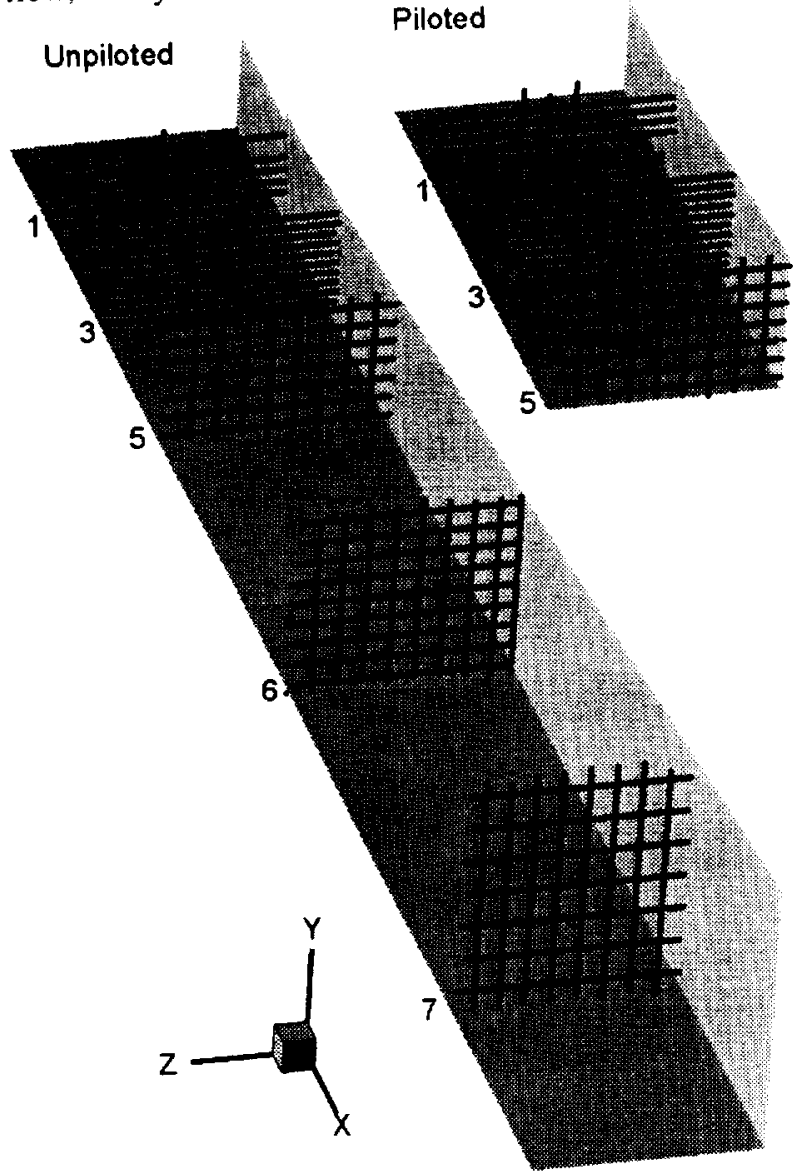

Figure 10 Cutaway views of data acquisition locations.

After obtaining the estimated mean temperature surfaces, the square of the deviation between measurement and mean at each of the measurement locations is evaluated. These squared deviation points are similarly fitted to a cosine series hivariate function of order 5. Standard deviation of these fits ranges from $78000 \mathrm{~K}^{2}$ to $190000 \mathrm{~K}^{2}$. Thus, the fitted function represents an estimate of the mean squared deviation distribution with uncertainty from $15000 \mathrm{~K}^{2}$ to $32000 \mathrm{~K}^{2}$. Or, taking typical values of uncertainty and mean square deviation then forming a percentage, uncertainty of order $\pm 25000 / 300^{2} \times 100= \pm 28 \%$. It should be emphasized that this large uncertainty is purely as a result of insufficient data points, i.e., as $n$ gets large it will become small. An additional error in mean squared deviation arises from CARS instrument precision. Expressed as a standard deviation, it was given as $\sim 100 \mathrm{~K}$. Thus, the experimental fitted mean squared deviation surface is everywherc of
AIAA-2002-0743

order $10000 \mathrm{~K}^{2}$ high due to instrument precision. Given these high levels of uncertainty and error, the mean squared deviation surface fits may be only qualitatively useful.

Figure 11 contains 3-dimensional cutaway views of the duct showing contour plots of the fitted temperature functions (left) and the square root of the fitted meansquare deviation functions, or rms (right). Flow direction is from top left to bottom right. Recall that the main fuel injector is on the top wall between planes 1 and 3 , and that the pilot injectors are at the top wall upstream of plane 1 .

Consider first the fitted mean temperature surfaces. At plane 1 in the unpiloted case the temperature is fairly uniform, between $1030 \mathrm{~K}$ and $1250 \mathrm{~K}$. The mean temperature for all the data points of this plane and case is $1162 \mathrm{~K}$. This mean compares favorably with the value computed assuming 1-D flow from the heater, which is $1187 \pm 60 \mathrm{~K}$. The fitted temperature is also reasonably uniform in the piloted case, despite the injection of pilot fuel upstream of this plane, except that the temperature drops close to the top wall, where the (cold) pilot fuel is injected. There is no indication of pilot fuel combustion in this plane.

At plane 3, in the unpiloted case, there is a region of low temperature which is the injected fuel plume, with temperatures as low as $\sim 250 \mathrm{~K}$ at the center. There is no evidence of combustion of the injected fuel at this plane. In the piloted case, there is a band of hot pilot fuel combustion products close to the top wall. The center of main fuel plume may be seen as a cool region with temperature as low as $\sim 650 \mathrm{~K}$, greater than in the piloted case, suggesting some combustion. Plane 5 is similar to plane 3. Temperatures have risen near the center of the fuel plume, to as low as $-550 \mathrm{~K}$ in the unpiloted case and $\sim 1250 \mathrm{~K}$ in the piloted. The height of the region of hot combustion products near the top wall in the piloted case has increased. At planes 6 and 7 in the unpiloted case, temperatures have risen abruptly as compared to plane 5 , suggesting nearly complete combustion (i.e., combustion which, if locally fuel rich, has consumed all available oxygen, or if fuel lean, has consumed all available fuel). The hot region close to the top wall (temperatures as high as $\sim 2300 \mathrm{~K}$ ), and to a lesser extent that near the bottom, are probably ones in which the fuel-air ratio is nearly stoichiometric. The cooler region near the center (as low as $\sim 1500 \mathrm{~K})$ is probably fuel rich. Injected fuel has probably not penetrated to the sidewalls $(-1200 \mathrm{~K}$ to $1300 \mathrm{~K}$ ). Data are not acquired at planes 6 and 7 in the piloted case due to lack of time. However, similarity in the pressure distributions between piloted and unpiloted cases

\section{American Institute of Aeronautics and Astronautics}


Unpiloted

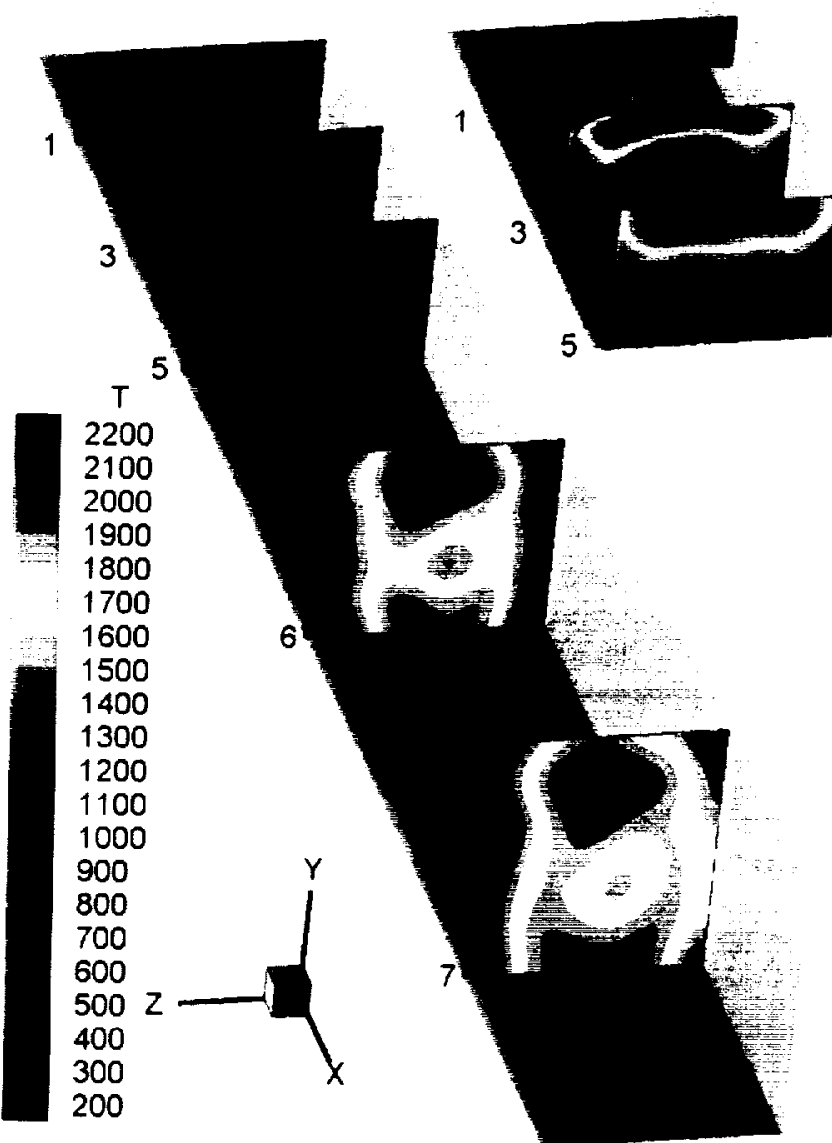

Piloted

Figure 11 Cutaway views of duct showing contours of mean temperature (left) and rms temperature (right) for unpiloted cases and piloted cases

downstream of about $x=0.75 \mathrm{~m}$ suggest that the temperature maps would be at least qualitatively similar. except perhaps close to the top wall.

Consider now the rms temperature surfaces. All the surfaces have irregular oscillations of amplitude $\sim 100 \mathrm{~K}$ that are probably simply due to random error. However. there are significant features present. At plane 1, unpiloted case the rms surface varies between $\sim 100 \mathrm{~K}$ and $\sim 230 \mathrm{~K}$. The standard deviations obtained from measurements at fixed points varied from $140 \mathrm{~K}$ to $220 \mathrm{~K}$. significantly greater than that inherent in the instrument $(\sim 100 \mathrm{~K})$. Thus, there are significant real temperature fluctuations in the flow exiting the heater. with standard deviation $\sim 100$ $K$ or greater. The rms level is comparable in the piloted case. except that it rises close to the top surface due to the pilot fuel plumes near the top surface.

Several regions of large temperature rms fluctuation
Unpiloted Piloted

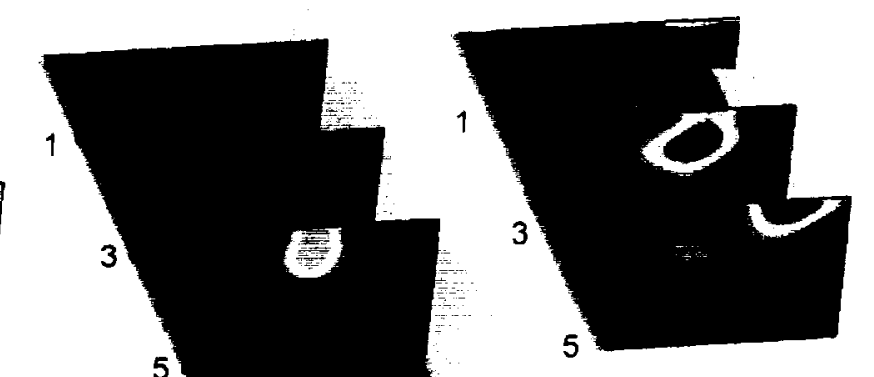

rms T
525
500
475
450

425

400

375

350

325

300

275

250

225

200

175

150

125

100 levels may be observed. In general, if combustion occurs. temperature variations arise due to variation in the local equivalence ratio (composition). Temperature variations also arise for fixed equivalence ratio due to variation in the extent of combustion, from no combustion to complete consumption of either fuel or oxidant. Thus, observed fluctuations may be due to intermittency in gas composition, intermittency in extent of combustion, or both. One such region, with peak rms level $\sim 440 \mathrm{~K}$, lies between the center of the fuel plume and the top wall, plane 5 , unpiloted case. A $2^{\text {nd }}$ such region with peak rms level $\sim 500 \mathrm{~K}$, lies near the fuel plume. plane 3. piloted case. In both cases, these regions appear to be in regions where combustion is just beginning or is incomplete. suggesting that intermittency in degree of combustion is the main cause of the fluctuations. The result for the unpiloted case is particularly interesting since there is

\section{American Institute of Aeronautics and Astronautics}


little indication of combustion in the mean temperature plots. One further region of large rms fluctuation level. with peak rms level $\sim 525 \mathrm{~K}$, lies on the right side near the top wall, plane 5. piloted case. The mean temperature is $2200 \mathrm{~K}$ at this location (much higher than for the other regions discussed). so the level of fluctuations normalized by the mean is much lower. It is believed that curve fitting accuracy is reduced at the edge of the data plane. Thus. this region may simply be explained by random error.

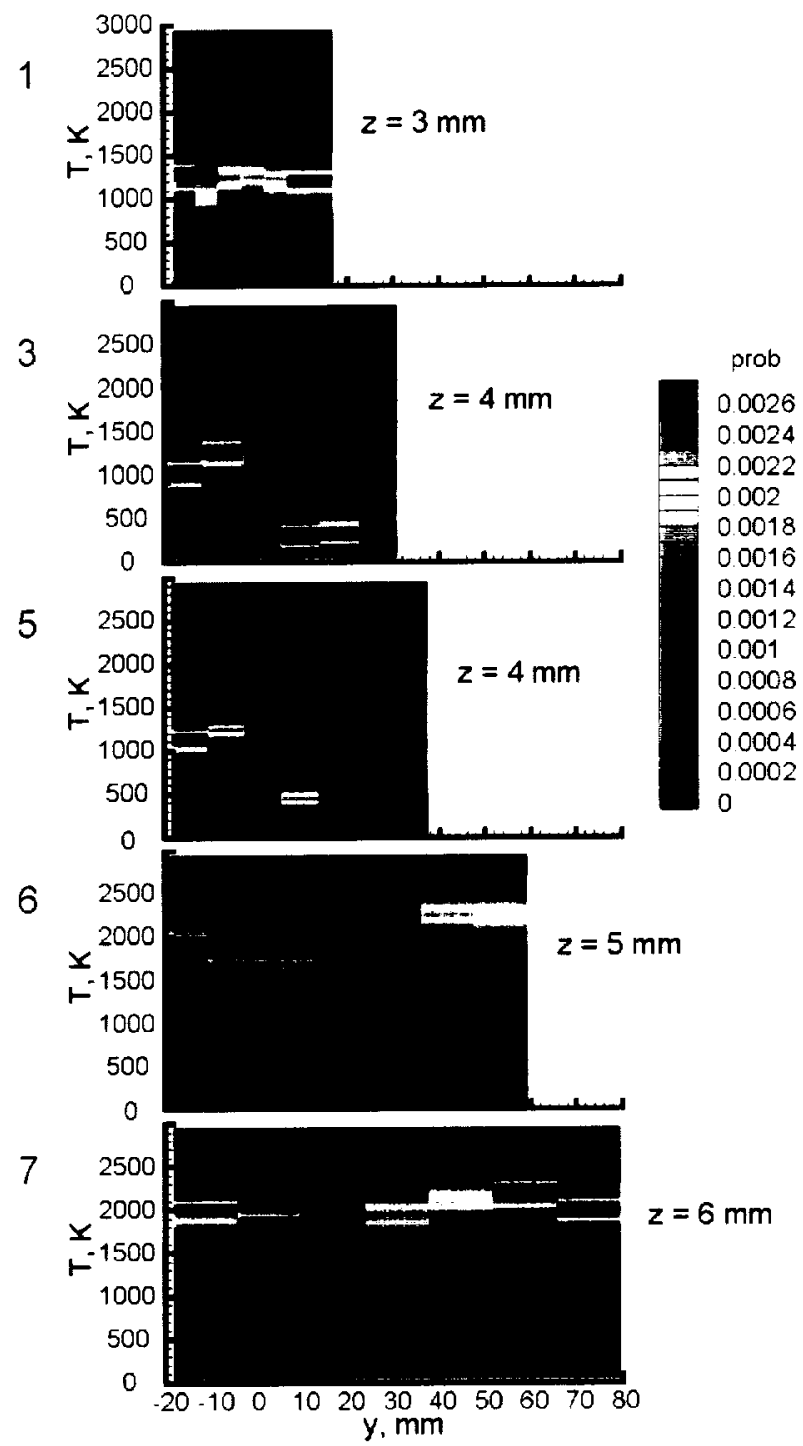

Figure 12 Probability density distributions of temperature near horizonal centerline, unpiloted.

Estimates of the probability density functions (pdfs) of temperature for several points near the horizontal centerline of each plane are presented in Figs. 12 and 1.3, for unpiloted and piloted cases respectively. These
AIAA-2002-0743

estimates are obtained by forming a histogram. with 100 $K$ wide bins, of each fixed-point data run. The histograms are normalized by the number of points in the run and bin width. In the figures the vertical axis is temperature and each PDF is represented by a vertical stripe centered on the $y$ location (horizontal axis) of the point. The color indicates probability denoted by the color map. The previously discussed regions of high rms levels are visible in these tigures as regions of broad pdts. However. it may be seen that these pdf's are not always symmetrical.

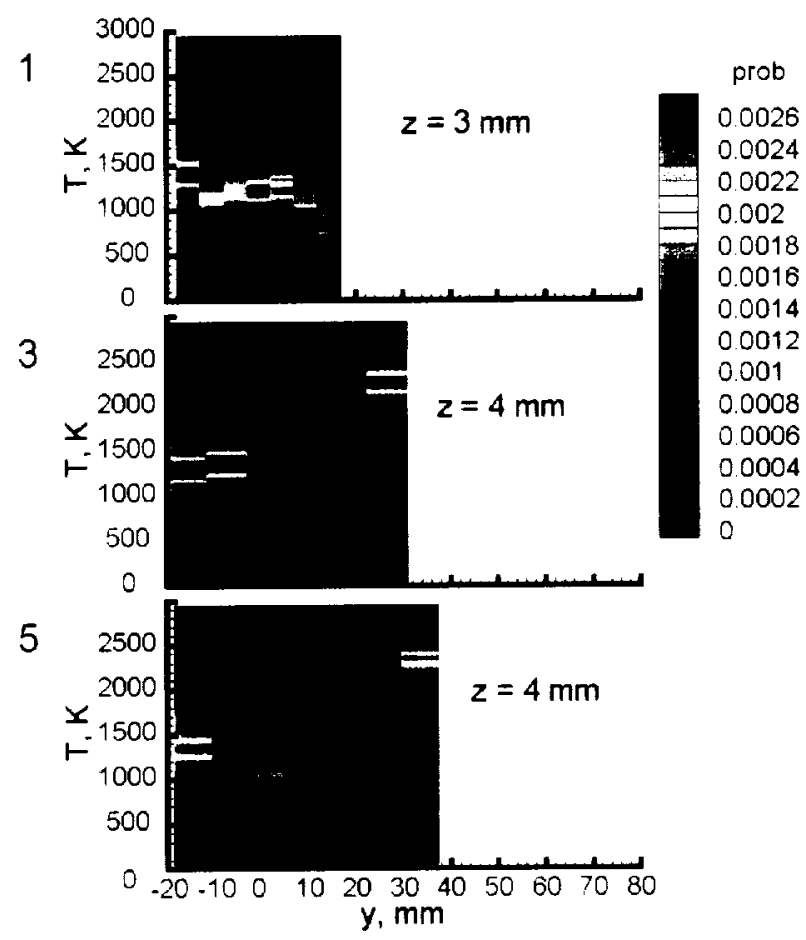

Figure 13 Probability density distributions of temperature near horizontal centerline, piloted.

The fitted mean and rms temperature surfaces. the temperature histograms, and the surface-pressure and heat-flux data provide a consistent description of the flow field. In the unpiloted case. no significant or only small and intermittent combustion of the injected fuel is observed ahead of $x=0.5 \mathrm{~m}$. Downstream of $x=0.75 \mathrm{~m}$ combustion appears nearly complete. In the piloted case. combustion of the pilot fuel appears to take place between $x=0.122 \mathrm{~m}$ (at the step) and $0.274 \mathrm{~m}$. There also appears to be significant combustion of the main injected fuel by this location. These results are not consistent with the CFD calculations performed prior to the commencement of the experimental work ${ }^{2}$, which predicted combustion in the vicinity of injection in both unpiloted and piloted cases. Consequently, this experiment provides a test case for CFD that is a more challenging than anticipated:

\section{American Institute of A eronautics and Astronautics}


accurate calculation will require accurate modeling of the chemical kinetics and turbulence-chemistry interactions as well as accurate modeling of the turbulent mixing.

\section{Conclusions}

CARS thermometry and modern design of experiments techniques have been successfully applied to a simple supersonic combustor. Functions that provide an estimate of the mean temperature and mean square deviation surfaces at various planes in the flow have been obtained. Histograms of temperature are presented. Additional data includes surface pressure and temperature. Boundary conditions and uncertainties are well characterized. and the data are useful for the validation of computational fluid dynamics (CFD) codes used in the design of supersonic combustors. Accurate calculation of the aggregate data set will require that the CFD code model both the turbulent mixing, and the turbulent kinetics and turbulence-chemistry interactions.

The support of the NASA Langley Research Center through grant NCC1-370 and contributions by Dr's J. P Drummond. M. W. Smith. and G. S. Diskin are gratefully acknowledged.

\footnotetext{
' Cutler. A. D.. White. J. A., "An Experimental and CFD Study of a Supersonic Coaxial Jet," AIAA Paper 2001-0143, 39 ${ }^{\text {th }}$ AIAA Aerospace Sciences Meeting and Exhibit. 8-1I Jan. 2001, Reno. NV.

¿Drummond. J. P.. A Two-Dimensional Numerical Simulation of a Supersonic Chemically Reacting Mixing Laver. NASA TM 4055, 1988.

${ }^{3}$ Drummond. J. P.. Diskin. G. S.. Cutler, A. D., "FuelAir Mixing and Combustion in Scramjets," Technologies for Propelled Hypersonic Flight, NATO Research and Technology Organization. Working Group 10, RTO Report AVT 10, January 2001.

'Eckbreth. A. C.. Laser Diagnostics for Combustion Temperature und Species, $2^{\text {nd }}$ Ed.. Combustion Science and Technology Series. Gordon and Breach, 1996. 'Smith. M. W., Jarrett. O. Jr., Antcliff, R. R., Northam. G. B.. Cutler, A. D.. Taylor, D. J., "Coherent antiStokes Raman spectroscopy temperature measurements in a hydrogen-fueled supersonic combustor," Journal of Propulsion und Power, Vol. 9. No. 2. 1993, pp. 163168.

"Direct-Connect Supersonic Combustion Facility, Facility Brochure. Wind Tunnel Enterprise, NASA Langley Research Center, www.wte.larc.nasa.gov. ${ }^{7}$ Auslender. A. H. "An Application of Distortion Analysis to Scramjet Combustor Performance Assessment," Final Report. 1996 JANNAF Propulsion
}

AIAA-2002-0743

and Joint Subcommittee Meeting Scramjet Performance Workshop, Dec. 12. 1996.

${ }^{8}$ Springer, R. R., Cutler. A. D., Diskin. G. S.. Smith, M. W., "Conventional/Laser Diagnostics to Assess Flow Quality in a Combustion-Heated Facility," AIAA Paper 99-2170, 35 ${ }^{\text {th }}$ AIAA/ASME/SAE/ASEE Joint Propulsion Conference and Exhibit. Los Angeles. CA. June 20-24, 1999.

"Antcliff, R. R., Hillard, M. E.. Jarrett, O. Jr., "Intensified silicon photodiode array detector linearity: application to coherent anti-Stokes Raman spectroscopy." Applied Optics, Vol. 23, No. 14, July 1984. pp. 2369-2375.

I" Eckbreth, A. C.. "Optical Splitter for Dynamic Range Enhancement of Optical Multichannel Detectors." Applied Optics, July 15. 1983.

"Clark. G.. Farrow, R. L., The CARSFT Code: User and Programmer Information. Sandia National Laboratories. Livermore. CA. Aug. 3, 1990.

${ }^{12}$ Yueh, F. Y.. Beiting, E. J.. "Simultaneous N.. CO. and $\mathrm{H}_{2}$ multiplex CARS measurements in combustion environments using a single dye laser." Applied Optics, Vol. 27. No. 15. Aug. 1988, pp. 3233-3243.

${ }^{13}$ Box, G. E. P., Hunter, W. G.. and Hunter, J. S., Statistics for Experimenters. An Introduction to Design.

Data Analysis, and Model Building. New York. Wiley. 1978.

${ }^{14}$ Cochran. W. G. and Cox. G. M., Experimental Designs. $2^{\text {nd }}$ Ed., Wiley Classics I ibrary Edition. New York. Wiley, 1992.

${ }^{15}$ Montgomery, D. C.. Design and Analysis of Experiments, $5^{\text {th }}$ Ed., New York, Wiley, 2001.

${ }^{\text {in }}$ Fisher, R. A., The Design of Experiments, $8^{\text {th }}$ Ed., Edinburgh. Oliver and Boyd. 1966.

${ }^{17}$ Box, G. E. P and Draper, N. R., Empirical Model Building and Response Surfaces, New York. John Wiley and Sons, 1987.

${ }^{18}$ Myers, R. H. and Montgomery, D. C., Response' Surface Methodology: Process and Product

Optimization Using Designed Experiments, New York. John Wiley \& Sons. 1995.

${ }^{19}$ Draper, N. R. and Smith. H.. Applied Regression Analysis. 3rd Ed.. New York, John Wiley and Sons. 1998 .

"Montgomery, D. C. and Peck. E. A.. Introduction to Linear Regression Analysis, $2^{\text {nd }}$ Ed.. New York. John Wiley and Sons, 1992.

${ }^{21}$ Table Curve 3D Version 3.0 User's Manual. AISN Software Inc.. www.spss.com. 1997.

\section{American Institute of Aeronautics and Astronautics}



